\title{
O coletivo do eu: \\ memória e educação das sensibilidades na experiência estética com a arte pública*
}

\author{
The collective of the self: memory and education \\ of sensitivities in aesthetic experience with public art
}

\section{Rita Márcia Magalhâes Furtado}

Pedagoga, doutora em Educação pela Universidade Estadual de Campinas e professora da Faculdade de Educação da Universidade Federal de Goiás rmmfurtado@uol.com.br

\section{Resumo:}

A arte presente nos espaços públicos da cidade é uma das possibilidades de interlocução do cidadáo com o coletivo, com o subjetivo e/ou com o singular e apresenta-se como uma forma de atribuir sentido, evocar as potencialidades da memória e estabelecer novos diálogos. Nesse sentido, esse trabalho objetiva uma reflexáo sobre as relações existentes entre os conceitos de experiência estética, educação das sensibilidades e arte pública, mediada pela compreensão do conceito de memória. A fenomenologia apresenta-se como modo mais efetivo de analisar a intersecçáo dos conceitos propostos.

Palavras-chave: Experiência estética; Arte pública; Memória

\section{Abstract:}

Works of art in public spaces enable citizens to interact with the collective, the subjective and/or the singular. They also create meanings, evoke memory potentialities, and establish new dialogues. Thus, this paper reflects on the existing relationships between the concepts of aesthetic experience, education of sensitivities and public art, having the concept of memory as its basis. A phenomenological approach is the most effective way to analyze such intersection of concepts.

Keywords: Aesthetic experience; Public art; Memory

* Trabalho apresentado no GT Memória e Educação das Sensibilidades 
"Atuando no corpo de forças da cidade, a arte é capaz de provocar marcas indeléveis em seus habitantes, torná-los sensiveis e criticos. Mais do que simples presença na cidade, a obra de arte propóe um encontro contínuo e reflexivo com o mundo".

Quintella e Masson, 2011: 479

L ste artigo busca compreender o modo como os elementos estéticos da arte pública se apresentam como eixo constituinte da experiência estética do espectador, mediados pela memória, e transpostos para as formas de manifestaçóes da coletividade. Tomando a fenomenologia como método referencial e a pesquisa bibliográfica com autores que abordam esses aspectos conceituais sobre múltiplos enfoques, este trabalho traz elementos que contribuem para a reflexão acerca das relações acima citadas.

A cidade, como local público de convívio, incorpora a soma de inúmeros elementos que a constituem: a história, o espaço físico, o lugar, a memória, o cotidiano, a rotina, a coletividade, a subjetividade, a singularidade. $O$ espaço público existe em função da pluralidade humana, envolvendo a complexidade das relaçôes socioculturais e, desse modo, incorpora, também, o campo artístico como o espaço que se sustenta em função da diversidade humana e suas articulaçôes com o mundo da arte. Esses espaços públicos assumem na contemporaneidade a condição de importantes articuladores do fragmento que cada vez mais caracteriza a sociedade e a cidade. Transitar pela cidade proporciona uma experiência ímpar que exacerba os contrastes, ao mesmo tempo em que confluem para os prazeres do caminhar, do observar detidamente os aspectos que comumente no dia a dia passam despercebidos.

Nesse sentido, a cidade se apresenta como possibilidade de construção da memória histórica, mas, sobretudo do reconhecimento da instituição da memória coletiva e das possibilidades da memória individual, "residual", que se constitui a cada novo elemento, acrescentado pelo cotidiano e pelas singularidades que permeiam esse cotidiano. Estes elementos ultrapassam a percepçáo do tempo cristalizado da memória para uma perspectiva dinâmica de produçáo e apropriação dos elementos que a constituem e impelem para os modos de "lembrar" coletivos. Modos estes que estabelecem o "lembrar ativo", a que se refere Gagnebin (2003: 44), o lembrar que quebra a inércia dos fatos acontecidos, porque ao recordar, estabelece conexôes com os acontecimentos das diversas temporalidades para buscar sua gênese e seus múltiplos sentidos e torna-se uma "memória compartilhada", pois inclui o outro. Andar pela cidade com os passos que "tecem lugares", desvela características e detalhes que provocam o olhar. Para Lopes, a experiência andante alarga as possibilidades de, pelo movimento do caminhar, experienciar-se o pensamento pré-reflexivo e reflexivo. Assim,

Um e outro embrenham-se em emoçôes, ligando o visível (a indiscutível materialidade do espaço urbano, a sua presença física, abrindo e fechando possibilidades, oferecendo barreiras às apropriaçóes, necessariamente finitas e enquadradas) ao invisível (memórias, sentimentos, sentidos), abrindo e construindo cenários interiores 
a partir de cenários exteriores, de tal forma que o que se cria é um ambiente de síntese inteiramente novo, autênticas topografias sentimentais ou poéticas práticas do espaço (LOPES, 2008: 106).

Desse modo, a arte presente nos espaços públicos é uma das variantes de interlocução do cidadáo com o coletivo e/ou com o singular e apresenta-se como um modo de atribuir sentido e estabelecer novos diálogos com os problemas e possibilidades do espaço público. Isto porque a arte consegue impregnar um objeto de puro sentimento, exteriorizando toda objetivação em sua interioridade, representando a ação e a emoção conjugadas no fazer do artista, o que reforça seu poder de comunicação, sua dimensão social.

\section{ARTE PÚbliCA: APROXIMAÇÓES CONCEITUAIS}

Dentre as múltiplas abordagens possíveis para tratar a temática da arte pública na contemporaneidade, a escolha para esse trabalho foi pela experiência estética do espectador enquanto possibilidade de educação das sensibilidades na interação com a arte pública, mediadas pela memória, que institui o coletivo. $\mathrm{O}$ conceito de arte pública é assim trabalhado por Regatão:

O termo arte pública se aplica às obras de arte inseridas principalmente em espaços exteriores e de "livre acesso público”. É necessário sublinhar que acessibilidade pública do espaço é condição obrigatória desse conceito e, para tal, não devem existir condicionamentos de ordem social ou econômica (REGATÃO, 2007: 64-65).

Para Bonomi, "arte pública é a celebração emotiva, de visualidade coletiva, localizada, permanente, gratuita, induzida e durável.” (2007: 19). Já Ricardo Silva a define de forma mais específica:

Entendemos a Arte Pública como um conjunto de objetos artísticos que, independentemente do processo que lhes deu origem, de quem os encomendou, financiou e é seu proprietário, estão colocados em contextos urbanos, de forma permanente ou temporária, facilmente acessível aos cidadãos, e que têm a capacidade de promover a identidade de um lugar junto dos seus fruidores, involuntários e maioritariamente não especialistas, proporcionando-lhes um maior contacto com a arte (SILVA, 2007: 45).

A obra de arte no espaço público não significa apenas sua inserção desarticulada dos vários elementos que a circundam, apenas pela vontade do artista ou da instituição que a financia, ela se dá também pela ruptura com o já dado, com a relação com as realidades que não são vistas, ou seja, com uma abordagem diferenciada que propicia um olhar que se cruza com o olhar do outro, em circunstâncias que alteram a ordem dos significantes, que aspiram uma percepção das reflexões instituídas pela interação desta presença do objeto estético. 


\section{EDUCAÇÃO DAS SENSIBILIDADES NA EXPERIÊNCIA ESTÉTICA \\ COM A ARTE PÚBLICA: UMA ABORDAGEM FENOMENOLÓGICA}

A estética, hiato divisor, mediador, catalisador e conciliador da arte e da filosofia, institui-se como a área do saber que lida desde sua gênese, com inúmeras antinomias tanto no mundo das formas como no mundo das idéias. São elas: o efêmero e o perene; o sensível e o inteligível; a presença e a ausência, o estático e o movimento, a ruptura e a continuidade. Mesmo que o termo "estética" traga a carga etimológica da sensibilidade, é a razão o que a legitima. Ela provoca deslocamentos do sentido e do significado, do racional e do sensível que se interagem no sentido de proporcionar ao espectador o aspecto pluriforme do mundo, bem como sua polissemia, refletindo o entrelaçamento de inúmeras manifestaçóes do real que extrapolam o circuito artístico, incorporando o que Dorfles chama de "elementos meta-artísticos, para-artísticos ou até anti-artísticos" (1988: 185). Isto ocorre, segundo ele, com "o advento do descontínuo, do assimétrico, do policêntrico nas criaçóes artísticas”; é talvez através destes elementos "que se poderá chegar a uma melhor possibilidade de entendimento recíproco entre os homens e não só no campo artístico" (DORFLES, 1988:190).

A identificação da experiência estética com a experiência fenomenológica está na própria experiência originária que é a do sentir, que antecede o ver, o pensar ou o compreender. É essa experiência que institui a presença do ser no mundo, que permite o aparecer do fenômeno. Desse modo, é preciso compreender que "a experiência estética exige uma operação análoga à redução fenomenológica e que a arte, como a fenomenologia, numa pesquisa das coisas mesmas, se orienta rumo a um retorno ao originário" (SAISON, 1999:126).

A relação do fenômeno com a consciência perceptiva evidencia a experiência vivida pelos sentidos percebidos como tais, com a suspensáo de todo conhecimento anterior, desprovido das certezas da ciência, preconcebido com um olhar neófito, inaugural do fenômeno. É a interrogação intermitente que permite se atingir com rigor fenomenológico, as movimentaçóes que indicam a ordem criadora. A encarnação de sentido, buscando as múltiplas possibilidades de manifestação do fenômeno, no mundo vivido, apresenta-se como uma atividade contínua, exigindo que todas as coisas "façam sentido" através da reflexão, cerne do pensar fenomenológico. Em geral, é a partir da visão que se efetiva a transcendência a plena abertura ao mundo, ao logos, que supera a mera representação do mundo através dos objetos. É no contato com um espaço doador de significado que a forma efetua uma "transformação constitutiva". No contato com a obra, que é uma transcendência, essa experiência permite "voltar ao estado nascente", aquele da indeterminação, da inquietação, da perturbação, mas também do inesgotável, do intenso, do desvelamento do novo, da cumplicidade, do indizível.

A existência da obra de arte no espaço público sustenta-se na relação da experiência do artista com a experiência do espectador. Para que essa relação se estabeleça, nela está contida, implicitamente, a relação sujeito-objeto, que determinará uma atitude fenomenológica. Há que se ressaltar a dinamicidade da arte pública no sentido de significação e reelaboração de seus aspectos constitutivos, pois enquanto produção simbólica está inserida nas relaçôes sociais concretas, produzindo significados que produzem tensôes entre o tradicional e o novo, que é o que pode produzir divergências, conflitos, e a partir daí, mudanças sociais significativas. Como nos diz Montes: 
Pelas formas plurais de expressão e seu compromisso com a diversidade da arte, tão multifacetária quanto os seus públicos, a arte pública pode oferecer o diálogo e a integração das diferenças, sem contudo anular a variedade de experiências que tais diferenças refletem (1998: 285).

Nesse sentido, busco em Mikel Dufrenne, filósofo francês com ampla produção na área da estética fenomenológica, os elementos que, mesmo se referindo à arte em geral, contribuem para se pensar a arte pública no sentido de identificar as os elementos invariantes da obra de arte, aqueles que na congruência desta se mantêm uniformes, presentes em todas as artes mesmo que em maior ou menor grau e que designam sua estrutura manifestada em três aspectos: o tratamento da matéria, a temática e a expressão.

No tocante ao primeiro aspecto, Dufrenne pensa a matéria como plano do sensível, diferenciando-se do material que origina esse sensível. Nesse sentido, o material, "instrumento materializado ou humano é como a matéria da matéria. Está a serviço da experiência estética, mas em princípio, como um servidor discreto, não aparece nela" (DUFRENNE, 1992: 378), sua aparição é minimizada para que apenas dê suporte, tornando-se como que coadjuvante do sensível. Em algumas artes, o material é inerente ao sensível, como no caso da arquitetura e da escultura, em que há uma transmutação do material e ele torna-se inseparável da matéria para a composição final do objeto estético. Desse modo, "o artista apenas luta com o material para que esse desapareça aos nossos olhos como material e seja exaltado como matéria (...) expondo-se e não ocultando-se" (DUFRENNE, 1992: 379)

O material que "se nega como coisa aparecendo", é como que a "linguagem" daquilo que Dufrenne chama de "esquemas harmônicos” responsáveis por uma aparição "sem equívoco" do sensível. A primeira função desses esquemas é a de definir, ordenar, classificar e selecionar os elementos presentes nesse meio de expressão estético, atingindo uma gama ampla de sons, cores, movimentos, linhas e superfícies, palavras e personagens. A segunda função é a de destacar alguns elementos que dáo à obra uma existência única, uma "tela de fundo" de significaçóes advindas da escolha do material por parte do artista e que "conferem ao sensível sua intensidade mais viva e sua presença mais veemente" (1992: 384). Aqui o ritmo, o tempo e o movimento são cruciais para que a obra faça sentido. Para que esse sentido seja pleno deve ser completado pela temática, contida na representação e na expressão, "que emana da obra enquanto totalidade" (1992: 387).

Então, o material transmutado em matéria é o pré-requisito para o segundo aspecto referenciado por Dufrenne como constituinte da estrutura da obra de arte: a temática. É esta que detém a "via da significação" e faz com que "o sensível da matéria se converta em signo" (1992: 388), por meio da representação que traz consigo o apelo ao conceito. A representação existe, diz Dufrenne, quando o objeto estético nos convida a deixar a aparência, o sentimento primeiro, "a imediatez do sensível” e buscar a reflexão que mostre a verdade desse objeto. Paradoxalmente, essa supressão do sensível é o que irá posteriormente exaltá-lo. E a temática escolhida pelo artista é imprescindível para que a representação revele a verdade plena do objeto estético. Essa verdade retrata a emoçáo despertada no artista, o que justifica sua escolha por uma dentre inúmeras outras possibilidades 
num determinado momento, já que "a obra é, em si mesma, sua própria temática” (DUFRENNE, 1992: 397). E essa emoção é elevada a um grau superior quando desperta uma significação afetiva e intelectiva.

Mas é ao terceiro aspecto da estrutura da obra de arte - a expressão - que Dufrenne atribui uma função maior, pois a obra inicialmente traz um mundo representado. É a imaginação enquanto categoria mediadora do conhecimento e da percepção que capta aspectos marginais desse mundo expressado no objeto estético e que desencadeia, em torno da temática, a importância da expressão. Esta é, para Dufrenne, "o que se conecta ao que é representado, embora signifique muito mais. (1992: 393). A percepção e a imaginação são então, elementos-chave para o discernimento da ambigüidade oferecida pela pluralidade de sentidos suscitados pelo objeto estético.

A percepçáo requer a cooperação da imaginaçáo e do entendimento e o resultado dessa cooperação resulta no que Dufrenne chama de "sentimento", entendido não como emoção, mas um tipo de conhecimento já que "revela um mundo", enquanto reação a "um mundo já dado". Este sentimento apresenta-se em vários graus e é uma resposta do ser inteiro e sua experiência acumulada para o objeto: a profundidade do objeto estético fala para a profundidade do ser. A experiência estética situa-se, então, na intersecção do sentimento com a reflexão. Assim, o processo perceptivo vai além da conversão do dado em inteligível, feito pela representação e pela retenção desse pelo entendimento. A percepçáo atinge uma dimensão metafísica quando se volta sobre essa experiência do conhecimento, eliminando o dualismo do "ser" e do "ter" com relação ao dado. Essa "comunhão" experimenta o contato com as coisas, abre espaço para a imaginação e efetiva a filtragem do entendimento, desembocando no sentimento, que não é o simples retorno à presença, mas uma nova relação com o imediato. $\mathrm{O}$ sentimento é, pois, conhecimento. E conhecimento que não é reflexivo, pois acolhe o afetivo, mas que representa um compromisso com relação ao mundo, que é sentido e não mais pensado.

O sentimento já possui um saber latente - e que, no entanto, não é reflexivo - que é reanimado quando no contato com o objeto estético. Como nos disse Fischer: "os nossos sentimentos impelem-nos para um esforço máximo de raciocínio e a nossa razão depura-nos os próprios sentimentos” (FISCHER, 1963: 13).

A atitude do espectador diante do objeto estético é, à primeira vista, um "deixar-se levar", uma união indispensável a toda relação, um "complementar-se". Assim, "o que conheço é o modo como ele se une a mim, e eu somente o conheço através dessa mistura que ele compóe comigo" (DUFRENNE, 1992: 527). O objeto estético impóe sua presença ao invés de se curvar à vontade do espectador. E esta possível submissão do espectador à imposição do objeto não significa passividade, mas antes uma condição primeira para que o objeto exprima sua profundidade e penetre na profundidade do ser que o contempla, evidenciando seu significado. É preciso adotar uma nova atitude diante da obra, submeter-se a ela, permitir que ela deposite no sujeito seu sentido, ser "fiel" a ela, compreender que, ao invés de gênese, há uma "autogênese" - uma participação do sujeito nesse objeto, que o faz reencontrar o movimento originário, o próprio movimento da obra, admitindo uma consubstancialidade, um estreitamento da afinidade, uma familiaridade -, abandonar a busca das causas exteriores que constituem a obra e, sobretudo, admitir uma busca de interioridade desta, uma necessidade inerente à existência.

Desse modo, “compreender a obra é assegurar-se de que ela não pode ser 
nada diferente do que ela é" (DUFRENNE, 1992: 491), é deixar-se penetrar pelo seu caráter inesgotável, é mergulhar em sua profundidade e submergir no sentimento estético, nessa abertura para o mundo que o objeto estético propicia. A experiência estética é, então, "uma espécie de oscilação perpétua entre o que poderíamos chamar a atitude crítica e a atitude sentimental" (DUFRENNE, 1992: 514). Se o sentimento pode, num primeiro momento, apresentar-se confuso, desconcertado, a reflexão dá a clareza ao sentimento que está no corpo e na inteligência.

A experiência estética acontece, então, na estreita relação com o mundo, por meio do corpo. Em todo processo de conhecimento há um encontro entre um "cognoscente" e um "conhecido", um "deparar-se com" do sujeito frente ao objeto, interligados numa correlaçáo que é, na sua essência, diferente, desigual, pois para o sujeito só é possível captar as propriedades do objeto quando sai de si, transcende, apreende o objeto em sua essência e isso só se dá com o retorno a si pela consciência e pela consciência de algo. Síntese da relação entre a estrutura e a gênese, o exterior e o interior, a experiência estética representa um "sair de si”, em busca de novas experiências, viver, conhecer e compreender o mundo do objeto em sua gratuidade, na comunicação originária, e retornar a si. A experiência estética torna-se assim, um modo de experimentar o mundo em suas várias possibilidades, de ser-no-mundo e de estar-no-mundo, sendo atravessado pelos acontecimentos, ao mesmo tempo em que se os atravessa. A passividade receptiva é um dos processos constitutivos da experiência que ao se converter em atividade, por sua vez inconclusa, retoma a abertura necessária ao receber.

Essa atitude de abrir-se para o mundo manifesta a capacidade de mudança, de criação, de transformação do ser humano, num movimento constante de, a partir desses processos interiores, inteirar-se dos processos exteriores. $\mathrm{O}$ comprometimento com o mundo, a abertura a uma participação mais efetiva, que não recusa o novo é um ato fundamental pelo qual o sujeito se constitui como unidade de percepção diante de um objeto estético, assumindo as composições do mundo, fazendo dessa abertura uma irrupção de percursos nômades. Essa percepção se apresenta com todas as tensões, interrogaçóes e sentidos da experiência vivida. A experiência estética que supóe a relação do objeto com a percepção é extremamente rica e é essa percepção que imerge o ser no mundo. Para que ocorra essa experiência, o espectador e o objeto estético não se polarizam, mas se invertem, se interagem e se complementam.

Tal experiência compreende uma relação entre o objeto e o sujeito concreto que mantém uma "relação viva com o mundo", contida na expressividade do artista ou na interpretação do espectador, sobretudo porque esta relação conduz ao sentimento, que é, para Dufrenne, o ápice de todo o processo perceptivo. No entanto, não se pode prescindir da reflexão, que, embora necessária, por si só não dá conta dessa experiência.

\section{CONSIDERAÇÓES FINAIS}

A arte pública, de um modo mais abrangente, representa a arte que possibilita aos cidadãos um contato com os elementos estéticos que remetem diretamente às suas vivências cotidianas e à memória coletiva, e que representam um contexto cultural como um todo, independente de que os cidadáos sejam ou náo um entendedores de arte, resultando que eles sintam prazer em fruir da matéria e das formas apresentadas. A forma expande-se para uma representação que in- 
voca a memória coletiva, evoca uma lembrança, ao mesmo tempo que, pela plasticidade da obra conjugada ao espaço no qual se insere, suscita novos elementos estéticos e artísticos. Convém aqui uma retomada ao pensamento de Halbwachs quando este afirma que quando se evoca uma memória, o que surge inicialmente enquanto lembrança é o plano do coletivo, dos acontecimentos e experiências de um determinado grupo. Assim,

Não é suficiente reconstituir peça por peça a imagem de um acontecimento do passado para se obter uma lembrança. É necessário que esta reconstrução se opere a partir de dados ou de noçóes comuns que se encontram tanto no nosso espírito como no dos outros, porque elas passam incessantemente desses para aquele e reciprocamente, o que só é possível se fizeram e continuam a fazer parte de uma mesma sociedade (HALBWACHS, 1990: 34).

Desse modo, a memória transcende os limites da consciência individual e estagnada nos acontecimentos comuns do cotidiano, passa a integrar-se ao espaço coletivo, ativando uma movimentação que vai de nós a nós mesmos, de nós mesmos com o outro e de nós e o outro com o coletivo, recompondo o passado e sedimentando o presente que pensa também o futuro. Para Certeau, "a memória mediatiza transformaçóes espaciais. Segundo o modo do 'momento oportuno' (kairós), ela produz uma ruptura instauradora. Sua estranheza torna possível uma transgressão da lei do lugar" (CERTEAU, 2007: 161) A arte, instaurada no espaço público, adquire autonomia, pois se desloca, se desvincula do cotidiano, estando no cotidiano, e ainda supera a ideia de rotina, de repetição inócua de açôes, para instaurar um novo paradigma de análise do termo, como o sentido que Pais nos traz, de rota, do latim rupta, ruptura, para dar uma multiplicidade de sentidos ao cotidiano. Então,

(...) se o quotidiano é o que se passa quando nada se passa - na vida que escorre, em efervescência invisível -, é porque 'o que se passa' tem um significado ambíguo próprio do que subitamente se instala na vida, do que nela irrompe como novidade ('o que se passou?'), mas também do que nela flui ou desliza (o que se passa...) numa transitoriedade que não deixa grandes marcas de visibilidade (PAIS, 2008: 30).

Segundo Dufrenne, não é possível ignorar que a consciência estética ocorra num mundo cultural que já está dado. A historicidade imbuída na obra de arte revela sua multiplicidade e sua potência indica uma "vontade de se realizar". Vários artistas criam inúmeras obras de arte, mas somente o espectador, através da percepção estética, pode fazê-la manifestar-se enquanto objeto estético. Nesse contexto há uma "dinâmica ontológica e estesiológica", pois é através dos sentidos que se dá o contato primeiro com o mundo, e são estes que promovem o desvelamento do objeto estético, que assume, por conta disso, uma exterioridade do aparecer ao mundo. O sentido da obra é suscitado pelo sensível, emana dele e, no entanto "o sentido é também um sentido inteligível” (DUFRENNE, 1992: 42). 
Através do sentido, o mundo exterior torna-se marginal e passamos a pertencer de algum modo, ao mundo do objeto estético.

Por fim, a pertinência da arte pública é de que esta, de certa forma, privilegia o espectador leigo, que na maioria das vezes, tem contato com a arte de maneira ocasional, diferentemente daquele espectador que vai ao museu ou outros espaços expositivos especificamente de maneira intencional para ter contato com a obra de arte. Além disso, a arte no espaço público permite uma melhor compreensão da cidade. A circulação dos cidadãos, cotidianamente, é reveladora de sua relação com a cidade, que pode ser de distanciamento ou de afinidade, já que esta relação ocasiona um novo modo de olhar para si próprios, reconhecendo-se como membros atuantes nesse espaço público, no sentido de permitir que, na interação com a arte pública, estes tenham autonomia de se utilizarem da sensibilidade, da reflexão, da interrogação, da admiração e até mesmo da indiferença. E nisso consiste sua importância maior.

\section{REFERÊNCIAS BIBLIOGRÁFICAS}

BONOMI, Maria. "Reflexóes". In: LAUDANNA, Mayra (org.). Maria Bonomi: da Gravura à Arte Pública. São Paulo: Edusp/Imprensa Oficial, 2007.

CERTEAU, Michel de. A Invenção do Cotidiano. 1-Artes de Fazer. Petrópolis, Vozes, 2007.

DORFLES, Gillo. Elogio da Desarmonia. Lisboa: Ediçóes 70, 1988.

DUFRENNE, Mikel. Phénoménologie de L'expérience Esthétique. Paris, PUF, 1992. v. I et v.II

FISCHER, Ernst. A Necessidade da Arte. Lisboa: Ulisseia, 1963.

GAGNEBIN, Jeanne-Marie. "O que significa elaborar o passado?” In: PUCCI, Bruno et al. Tecnologia, Cultura e Formação...Ainda Auschwitz. São Paulo: Cortez, 2003.

HALBWACHS, Maurice. A Memória Coletiva. São Paulo: Vértice, 1990.

LOPES, João Teixeira. "Andante, andante: tempo para andar e descobrir um lugar”. In: ARAÚJO, Emília. DUARTE, Ana Maria. RIBEIRO, Rita. (orgs.). O tempo, As Culturas e as Instituiçóes: Para Uma Abordagem Sociológica do Tempo. Lisboa: Ediçóes Colibri, 2008.

MONTES, Maria Lúcia. "Arte pública e cultura brasileira”. In: Anais dos Seminários de Arte Pública. São Paulo: SESC, 1998.

PAIS, José Machado. Sociologia da Vida Quotidiana. Lisboa: ICS, 2007.

QUINTELLA, Ivy Pessôa. MASSON, Michel. "As incorporaçôes das açóes urbanas na cidade contemporânea”. In: CIRILLO, José. VENEGAS, Carolina. RODRIGUEZ, Teresa Espantoso. (orgs.). Arte Público y Espacios Políticos: Interacciones y Fracturas en las Ciudades Latinoamericas. Belo Horizonte: C/ Arte, 2011.

REGATÃO, José Pedro. Arte Pública e os Novos Desafios das Intervençôes no Espaço Urbano. Lisboa: BonD, 2007.

SAISON, Maryvonne. "Le tournant esthétique de la phénoménologie". Revue d'Estétique. Paris, n.36, 1999.

SILVA, Ricardo Jorge dos Reis. "Arte pública como recurso educativo: contributos para a abordagem pedagógica de obras de arte pública”. Lisboa: Faculdade de Belas-Artes/UL, 2007. (Dissertação de Mestrado) 